\title{
Stabilization of Firing Range Soil Using Cuttlefish Bone
}

\author{
Deok Hyun Moon* \\ Department of Environmental Engineering, Chosun University, \\ Gwangju, Republic of Korea \\ *dhmoon@chosun.ac.kr
}

Firing range soil is seriously contaminated with lead $(\mathrm{Pb})$ and copper $(\mathrm{Cu})$ because of bullet fragments generated during range operation which are mainly composed of $\mathrm{Pb}$ and $\mathrm{Cu}$. The firing range was operated for many years without remediation and therefore high levels of $\mathrm{Pb}$ and $\mathrm{Cu}$ could be accumulated in the range soils. Lead $(\mathrm{Pb})$ and copper $(\mathrm{Cu})$ are known to be very toxic to the human body and caused serious health problems. Therefore, in this study the remediation of firing range soil was conducted to reduce the risk of $\mathrm{Pb}$ and $\mathrm{Cu}$ effects in contaminated soil.

As a remediation process, the stabilization technique was applied to the contaminated soil. The stabilization process is widely used to immobilize heavy metals/metalloids in contaminated soil.

In the past, cement, hydrated lime, quicklime, cement kiln dust and fly ash, etc. have been widely used as stabilizing agents. However, recently natural waste has received great attention.

In this study, pulverized cuttlefish bone (-\#10 mesh materials) (CFB) was used to immobilize $\mathrm{Pb}$ and $\mathrm{Cu}$ in contaminated soil. Moreover, calcined cuttlefish bone (CCFB) was used as a stabilizing agent in order to compare its effectiveness to the natural state of cuttlefish bone. The dosages of CFB ranged between $2 \mathrm{wt} \%$ and $10 \mathrm{wt} \%$ while the CCFB ranged from $1 \mathrm{wt} \%$ to $5 \mathrm{wt} \%$. The stabilized samples were cured for 1 week. Following the curing period, stabilization effectiveness was evaluated with a $0.1 \mathrm{~N} \mathrm{HCl}$ extraction for both $\mathrm{Pb}$ and $\mathrm{Cu}$.

The stabilization results showed that the leachability of $\mathrm{Pb}$ and $\mathrm{Cu}$ decreased with increasing dosages of CFB and CCFB. A reduction of approximately $94 \%$ and $97 \%$ in $\mathrm{Pb}$ leachability was obtained with the $8 \mathrm{wt} \% \mathrm{CFB}$ and the $3 \mathrm{wt} \% \mathrm{CCFB}$ treatments, respectively. Moreover, a reduction of approximately $97 \%$ and $99 \%$ in $\mathrm{Cu}$ leachability were attained upon $6 \mathrm{wt} \%$ CFB and 2wt $\%$ CCFB treatments, respectively.

Overall, the stabilization results indicated that the CFB and CCFB can be beneficially used for the simultaneous immobilization of $\mathrm{Pb}$ and $\mathrm{Cu}$ in contaminated soil. 